\section{TUBERCULOSIS: A GLOBAL STUDY IN SOCIAL PATHOLOGY}

By John B. McDougall, C.B.E., M.D., F.R.C.P.Ed. Pp. viii +455 , with 29 illustrations. Edinburgh: E. and S. Livingstone. 1949. 32s. $6 \mathrm{~d}$.

Dr. McDougall's work for the tuberculosis section of the W.H.O. has given him an unrivalled position for a survey of the state of the nations in respect to tuberculosis. His book consists of three main parts. The first is statistical, the second discusses the various factors which influence the morbidity and mortality of tuberculosis in different communities, and the third, though its title suggests that it is to be confined to methods of investigating the tuberculosis status of a community, does in fact tackle most of the problems of organizing a tuberculosis health service. The second and third sections might almost have been entitled together ' a review of recent advances in the epidemiology and prevention of tuberculosis.' There are a few minor omissions and possibly some looseness of arrangement in places, but in general these sections combine a very near approach to textbook thoroughness with the breadth of vision and command of illustrative example of one who has seen as much of the relevant world as anybody.

The first part of the book is, however, by far the most immediately valuable; it is a lesson not only in tuberculosis but in economic geography, and the variousness of mankind. Basically it is an account of the available statistics of all those countries for which any statistics are available, but it is enlivened by a running commentary on the reliability and the significance of the figures. The state of civilization of a country is probably as accurately reflected in its tuberculosis statistics as in any other available figure. Between the results of the exact and fruitful survey of the Riverside Sanatorium District of Minnesota and the inaccurate but alarming figures available for most of Africa there is a gulf as wide as that between the Comet and a dug-out canoe. This is a most valuable and stimulating book, a book to be read with profit for much more than its obvious immediate value in the field of tuberculosis, by all who are interested in the health of the world.

\section{B.L.}

\section{THE MEDICAL ANNUAL}

Edited by Sir Henry Tidy and Prof. A. Rendle SHORT, with 45 contributors. Pp. 450, with 79 illustrations and 50 plates. Bristol: John Wright. 1949. 25 s.

The 67th issue of this old favourite is on the market once again, and is as welcome as ever. There can be few publications of comparable size which contain such a wealth of information of all sorts. In the review of the year's work, short articles are presented in alphabetical order dealing with a multitude of topics from 'Abdominal In- juries ' to 'World Health Organization.' The book includes a description of new pharmaceutical products, medical and surgical appliances, together with a most valuable list of English and American medical works and new editions published during the past 12 months, arranged under subject headings.

A reviewer cannot do justice to the many excellent annotations with which he is here presented in the small compass of a short notice such as this must be, but he can give a random sample of the contents with the belief that it will intrigue the reader.

Professor Rendle Short, the surgical editor, discusses cholangiography and manometry of the common duct in the diagnosis of either stenosis or atony of the sphincter of Oddi, a form of investigation more common on the Continent than in this country. French and Italian surgeons believe that symptoms of biliary colic can be due to both too great and too little tone in the sphincter. Treatment of the former is transduodenal division of the ring of muscle under manometric control; of the latter, either drainage of the biliary tract if there is infection, or splanchnicectomy if there is none.

Norman Tanner deals with the present position of vagotomy for the treatment of peptic ulcer. He inclines to the view that this operation is not indicated for gastric ulcers as gastric resection gives such good results in these cases. Moreover such ulcers may be or may become carcinomatous. Vagotomy is most useful for relieving patients who have developed anastomotic ulcers following gastrectomy or gastro-jejunostomy.

From Dr. Stanley Banks comes an interesting article on the incidence of foetal abnormalities arising when the mother has suffered from rubella during the first two months of pregnancy. He points out that other infectious diseases, with the exception of poliomyelitis, do not have similar foetal effects.

Professor Lambert Rogers writes on the results of surgery of the breast, and points out that the best results from surgery alone are not inferior to those obtained by the combination of surgery and radiotherapy.

Dr. Una Ledingham paints a grim picture of the atomic bomb injuries received by the unfortunate inhabitants of Nagasaki, and the equally unfortunate animals used in the Bikini experiments.

New work on aureomycin is described by Dr. Andrew Wilson. This new antibiotic, derived from streptomyces aureofaciens has been shown to be active against certain virus diseases as well as against urinary tract infections resistant to both penicillin and streptomycin. It is effective in the. treatment of lymphogranuloma, while penicillin has now replaced malaria in the management of neurosyphilis.

Mr. Norman Barrett discusses coarctation of the aorta, operative treatment for which was first carried out as late as 1944 by Crafoord of Stockholm. He also gives an up-to-date account of the surgical 
treatment of congenital abnormalities of the heart and great vessels. Dr. Langton Hewer reviews the work of Rait Smith and Ostlere on anaesthesia for these cases, and points out that they prefer semiclosed ether in preference to cyclopropane because of the cardiac irregularities resulting from the latter gas.

Mr. Pennybacker writes on the surgical treatment of Parkinson's disease, discussing the surgical removal of areas of cerebral cortex, and division of some of the fibres of the internal capsule, techniques designed to relieve tremor.
There is an interesting section on carcinoma of the bronchus, and the need for early diagnosis is emphasized, so that surgery can have a greater chance of success. Persistent cough, slowly resolving and recurring pneumonia, and chest pain may be some of the early symptoms, while the great value of radiology and bronchoscopy in diagnosis is stressed.

Sir Henry Tidy has not contributed himself but as co-editor he has guided his strong medical team with skill and discrimination.

J.A.L.

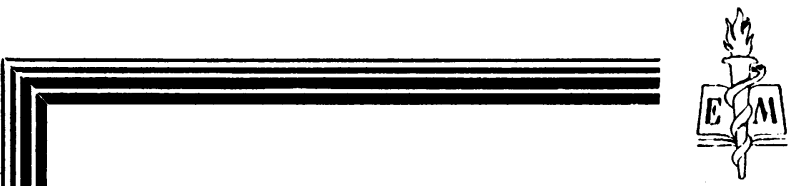

INTERNATIONAL MEDICALABSTRACT SERVICE EXCERPTA MEDICA

Fifteen separate monthly sectional journals containing abstracts in English from every available medical journal in the world and covering the whole field of clinical and experimental medicine

Write for a prospectus or specimen copy mentioning your speciality E. \& S. LIVINGSTONE, LTD., 16/17 TEVIOT PLAGE, EDINBURGH 1 Sole distributors for Great Britain and the British Dominions

\section{RUTHIN CASTLE, NORTH WALES}

A Clinic for the diagnosis and treatment of Internal Diseases (except Mental or Infectious Diseases). The Clinic is provided with a staff of doctors, technicians and nurses.

The surroundings are beautiful. The climate is mild. There is central heating throughout. The annual rainfall is $\mathbf{3 0 . 5}$ inches, that is, less than the average for England.

The Fees are inclusive and vary according to the room occupied.

For particulars apply to THE SECRETARY, Ruthin Castle, North Wales. 